Bangladesh Journal of Neuroscience 2011; Vol. 27 (2) : 78-82

\title{
'Invasion of Meningioma Cell in Bony Hyperostosis- an Observational Study of 34 Cases'
}

\author{
A. M. REJAUS SATTER ${ }^{1}$, K. A. TALHA ${ }^{2}$, FARZANA RASHID ${ }^{3}$, FARHANA SELINA ${ }^{4}$, \\ MD. MAMUN KHAN ${ }^{5}$, AT M MOSHAREF HOSSAIN ${ }^{6}$, ABDUL KADER SHAIKH ${ }^{7}$.
}

\begin{abstract}
:
Background: Meningiomas are usually globular encapsulated tumors. They are extra axial tumors attached to dura and compress the underlying brain without invading it. Abnormalities of bone are frequently encountered in Meningiomas. Hyperostosis or endosotsis are certainly more common than destruction of bone. Aims and Objective: Aim of study was to observe the percentage of tumour cell invasion in to the hyperostosis part of intracranial meningiomas. Materials and methods: This is an observational analytic study. Sample size was 34. Place of study was department of Neurosurgery of Square Hospitals Ltd. All the patients with the histological diagnosis of meningioma were included in to this study. Result: Female patients were predominant. Highest number of patients was from 41 to 50 years age group. Convexity meningiomas were commonest (35\%) followed by parasagittal meningiomas. According to histopathological subtype meningothelimatous was commonest (56\%) followed by psammomatous. About one fourth meningioma patients (26.47\%) presented with hyperostosis. Among the hyperostosis patients in $44.44 \%$ patient's cause of hyperostosis was due to tumour cell invasion into hyperostosis part. Conclusion: Tumour cell invasion is one of the causes of hyperostosis in intracranial meningiomas which was responsible in more than one third cases in this study.
\end{abstract}

Key words: Hyperostosis, tumour cell invasion, meningioma.

\section{Introduction:}

Meningiomas are usually globular encapsulated tumors. They are extra axial tumors attached to dura and compress the underlying brain without invading it. Even though invasion of dura and dural sinuses are common in meningiomas, they are usually separated from the piamater. Meningiomas are defined as neoplasm composed of meningothelial cells originating from arachnoid cap cells ${ }^{1}$.

Meningiomas can occur in any age groups. Its incidence increases with age and occur mainly in middle age and old age. The peak incidence is around 45 years. In adult meningiomas shows female predominance at a ratio of male $:$ female $=1: 1.4^{1}$.
Abnormalities of bone are frequently encountered in Meningiomas. But it is very difficult to appreciate the exact frequency of bony reaction and / or invasion, because very few series mention this particular aspect. Hyperostosis or endosotsis are certainly more common than destruction of bone, and were found in $25 \%$ of Cushing cases ${ }^{2}$. Sosman and Putnam reported Roentgenological "osteomatous change" in 49\% of their cases ${ }^{3}$.

An extensive Hyperostosis can occur with a small Meningeal tumor, a fact already pointed by Cushing, who separated hyperostoing 'en plaque' Meningiomas from bone alterations accompanying 'global' or 'en mass' Meningiomas.

1. Specialist, Neurosurgery, Square Hospitals Ltd.

2. Consultant, Neurosurgery, Square Hospitals Ltd.

3. Asst. Registrar, ICMH, Dhaka

4. Specialist Anesthesiology, Square Hospitals Ltd.

5. Clinical staff, Neurosurgery, Square Hospitals Ltd.

6. Professor of Neurosurgery, BSMMU

7. Asst. Prof. Neurology, BSMMU 
Several theories have been put forward by Patrick J. Derome \& A. Visot of department of Neurosurgery of FOCH hospital, Suresnes Cedex, France to explain bone formation and / or destruction. Slight movement of sagittal suture and bregma, including a stimulating effect on the cells of pachymeninges, explain the frequency of hyperostosing en mass meningiomas in the parasagittal area $^{4}$. In vascular theory, a disturbance of circulation in the bone, subsequent to presence of meningioma, is responsible for hyperostosis ${ }^{5}$. Phemister and others suggested that the meningioma irritates the periosteum, leading to osteoblastic proliferation which leads to hyperostosis ${ }^{6}$. Finally, Freedman and Forster demonstrated that " the tumor cells themselves take an active part in the production of the hyperostosis is rather than acting only as relative foreign bodies to stimulate bone growth; tumor cells of meningiomas can produce fibroblasts, osteoblast and osteoclasts or act as the latter two without apparent morphological alteration? .

Diagnosis of a hyperostosing meningioma is easily made by computerized tomography (CT) scan of brain (Fig.-1) and magnetic resonance imaging (MRI) of brain. Plain X-rays, tomography and CT scan allow the surgeon to determine the boundaries of bone involvement with relative accuracy.

\section{Materials and methods:}

This is an observational analytic study titled 'invasion of meningioma cell in bony hyperostosis- an observational study of 34 cases'. Study place was neurosurgery department of Square Hospitals Ltd. Total number of cases were $34(\mathrm{~N}=34)$. All the patients with the histological diagnosis of meningioma were included in to this study. Patients who didn't consented to be included or histological diagnosis other than meningioma were not included. Study period was May 2007 to April 2010.

Aim of this study was to observe the percentage of tumour cell invasion in the bony hyperostosis in intracranial meningioma patients.

After confirmation of diagnosis as meningioma, patient's data were collected by questionnaire. Meningioma was confirmed by histopathology report and hyperostosis of bone was confirmed by CT scan of brain and intra-operative findings. Hyperostosis area of bone was drilled out and was sent for histopathology to confirm presence of meningioma cell in it.

All questionnaires were collected at the end of data collection and were tabulated according to different parameters. Study results were also compared with those of other studies.

\section{Results:}

This is an observational analytic study titled 'invasion of meningioma cell in bony hyperostosis- an observational study of 34 cases'. Total number of cases was 34. Data were tabulated according to different parameters.

Table-I

Distribution according to sex $(N=34)$

\begin{tabular}{lccc}
\hline Sex & No. of case & percentage & Ratio \\
\hline Male & 13 & $38 \%$ & $1: 1.6$ \\
Female & 21 & $62 \%$ & \\
\hline
\end{tabular}

Table-I shows the distribution according to sex. Most of patients were female. They were $62 \%$ of total cases. Male is to female ratio was $1: 1.6$

Table-II

Distribution according to age group ( $N=34)$

\begin{tabular}{lcc}
\hline Age frequency (years) & No. of case & Percentage \\
\hline$<20$ & 00 & $00 \%$ \\
$21-30$ & 01 & $2.9 \%$ \\
$31-40$ & 09 & $26.5 \%$ \\
$41-50$ & 12 & $35 \%$ \\
$51-60$ & 07 & $21 \%$ \\
$>60$ & 05 & $14.7 \%$ \\
\hline
\end{tabular}

Table-Il demonstrates the distribution patients according to age group. Highest number of patients was from 41 to 50 years age group. They were 35\% of all patients. Near about one fourth patients were from 31 to 40 years age group. Next common was 51 to 60 years age group followed by more than 60 years age group. There was only one patient in 21 to 30 years age group. 
Table- III

Distribution according to location ( $N=34)$

\begin{tabular}{lcc}
\hline Location of meningioma & No. of case & percentage \\
\hline Convexity & 12 & $35 \%$ \\
Parasagittal & 08 & $21.5 \%$ \\
Sphenoid wing & 05 & $14.7 \%$ \\
Tentorial & 01 & $2.9 \%$ \\
Petroclival & 02 & $5.8 \%$ \\
Suprasellar & 02 & $5.8 \%$ \\
Olfactory groove & 03 & $8.8 \%$ \\
Falcine & 01 & $2.9 \%$ \\
\hline
\end{tabular}

Table-III presents distribution of all patients according to the location of meningiomas. More than one third patients were operated for convexity meningiomas. Second highest was parasagittal meningiomas which was $21.5 \%$ of all meningiomas. Number of sphenoid wing meningiomas was 5. Other locations were tentorial, petroclival, suprasellar, olfactory groove and falcine.
Table-IV

Distribution according to histopathology subtype $(N=34)$

\begin{tabular}{lcc}
\hline Histological subtype & No. of case & percentage \\
\hline Meningiothelimatous & 19 & $56 \%$ \\
Psammomatous & 05 & $14.7 \%$ \\
Atypical & 04 & $11.7 \%$ \\
Angiomatous & 04 & $11.7 \%$ \\
Transitional & 01 & $2.9 \%$ \\
Malignant & 01 & $2.9 \%$ \\
\hline
\end{tabular}

Table-IV illustrates the distribution of all meningiomas according to their histopathological subtypes. More than half (56\%) meningiomas were of meningothelimatous subtype. Psammomatous subtype was $14.7 \%$. Number of atypical and angiomatous subtypes was same and they were $11.7 \%$ of total cases. Transitional and malignant subtypes had only 1 case in each group.

Table-V

Distribution according to hyperostosis and tumour cell invasion

\begin{tabular}{ccccc}
\hline Number of case & $\begin{array}{c}\text { No. of } \\
\text { hyperostosis }\end{array}$ & $\begin{array}{c}\text { Percentage of } \\
\text { hyperostosis }\end{array}$ & $\begin{array}{c}\text { Number of cases } \\
\text { of tumour cell } \\
\text { invasion }\end{array}$ & $\begin{array}{c}\text { Percentage of } \\
\text { cases of tumour } \\
\text { cell invasion }\end{array}$ \\
\hline 34 & 09 & $26.47 \%$ & 04 & $44.44 \%$ \\
\hline
\end{tabular}

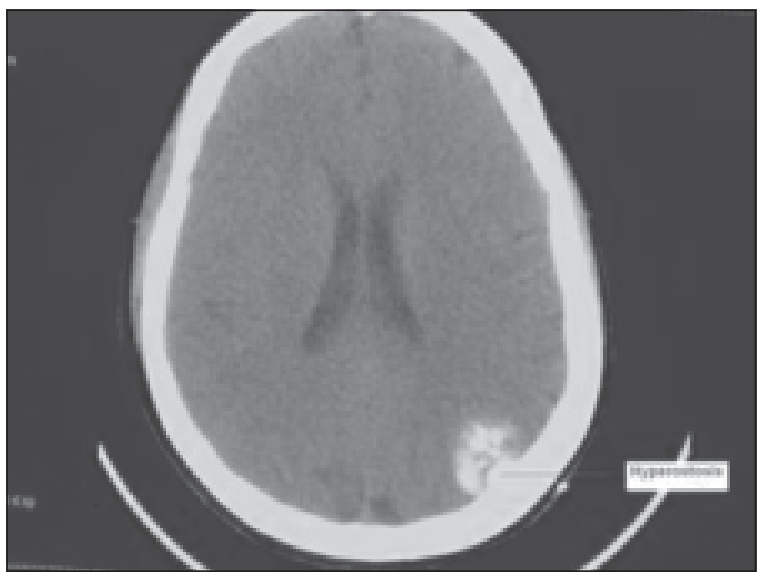

Fig.-1: CT scan shows meningioma with bony hyperostosis.jpg

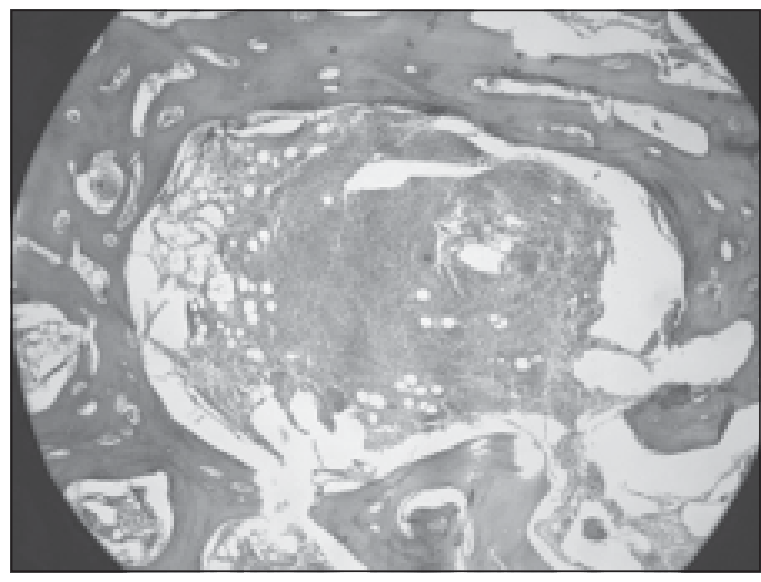

Fig.-2: Histopathological slide shows meningioma cell inva.jpg 
Table- $V$ shows the distribution of all 34 patients according to bony hyperostosis and tumour cell invasion in the hyperostosis area. About one quarter (26.47\%) meningioma presented with bony hyperostosis. Among 9 hyperostosis patients tumour cell invasion was observed in 4 cases. That means $44.44 \%$ of bony hyperostosis was due to tumour cell invasion.

\section{Discussions:}

This study was performed to observe the percentage of tumour cell invasion into hyperostosis part of intracranial meningioma. Total number of cases was 34 .

Bony reaction is a very important clinical presentation for intracranial meningiomas. Sosman and Putnam found $49 \%$ hyperostosis cases in their series ${ }^{3}$. Cushing and Eisenhardt found $25 \%$ hyperostosis cases in their series ${ }^{6}$. Their study was performed in pre-CT scan time, so confirmation of hyperostosis was done only by $X$ ray and intra-operative findings. According to the study of Balasubramanium et al they had $17.3 \%$ of cases presented with bony reaction ${ }^{8}$. In our series hyperostosis was confirmed in $26.47 \%$ of cases. Diagnosis of hyperostosis was made on the basis of CT scan, intra-operative findings and histopathology, but due to early diagnosis of meningioma and short waiting time for surgery number of hyperostosis cases may be less then other studies. More than one fourth intracranial meningioma patients presented with hyperostosis.

Study on relationship between bony reaction and age group are very few in number. Guthric et al distributed hyperostosis cases according to age group 9 . He found that in adult cases $44 \%$ of cases were presented with hyperostosis. In our study, all patients were adult to old age group and there was no pediatric age group patient and percentage of patients presenting with hyperostosis was $26.47 \%$.

Pieper et al reported their study on 51 patients with hyperostosis. They found tumour cell invasion in $69 \%$ of cases. That means histological examination of the resected bone showed tumor invasion in 35 patients ${ }^{5}$. In our study tumour cell invasion in hyperostosis was observed in $44.44 \%$ cases.
There are three types of meningiomas according to malignancy grades: benign (WHO grade I), atypical (WHO grade II), and anaplastic (malignant; WHO grade III) meningiomas. About $80 \%$ of all meningiomas are slow-growing tumours of WHO grade I. Any histological variant is compatible with WHO grade I, except for the chordoid, clear-cell, papillary, and rhabdoid meningiomas, which are consistently associated with more aggressive clinical features. The histological variants most commonly diagnosed in pathology specimens are meningothelial, fibrous, and transitional meningioma. Atypical meningiomas constitute $15-20 \%$ of meningiomas. Atypical, clear cell and choroids meningiomas are under WHO grade II. Anaplastic meningiomas account for $1-3 \%$ of all

meningioma cases. Apart from anaplastic meningiomas rhabdoid and papillary meningiomas are also malignant meningiomas under WHO grade $\mathrm{III}^{10}$.

According to the study of Jellinger et al meningothelimatous and transitional forms constituted $71.5 \%$ of intracranial tumors, fibroblastic forms $7.5 \%$ and highly vascularized meningiomas $5.2 \%$ of the intracranial tumors, while true "angioblastic" meningiomas (hemangioblastomas and hemangiopericytomas) amounted $3.1 \%$ of the intracranial meningiomas, $1.2 \%$ were "atypical" (socalled malignant) meningiomas ${ }^{11}$. According to this study meningothelimatous and transitional forms constituted $58.9 \%$ of all meningiomas. Angiomatous and atypical subtypes were confirmed in $11.7 \%$ cases respectively.

When the results of this study were compared with those of other studies a fair similarity was observed. There were few limitations of this study; study sample was not very large and comparison was done by significant test.

\section{Conclusion:}

In summary it can be said that tumour cell invasion is one of the cause of hyperostosis in intracranial meningiomas which was responsible in more than one third cases in this study. 


\section{References:}

1. Chau SM, Miles JM. The pathology of meningiomas. In: Al- Mefty $\mathrm{O}$, ed. Meningiomas. New York: Raven Press, 1991: $37-56$.

2. Cushing $\mathrm{H}$, Eisenhardt L. Meningiomas, their classification, regional behavior, life history and surgical end result. In: Thomas CC, ed. Meningioma. Illinois: Springfield, 1938: 785.

3. Sosman MC, Putnam TJ. Roentgenological aspects of brain tumors- meningiomas. Am J Roentgenol 1925; 13: 1- 12.

4. Patrick J, Visot DA. Bony reaction and invasion in meningiomas. Meningiomas 1991; 169-178.

5. Pieper DR, Al-Mefty O, Hanada Y, Buechner D. Hyperostosis associated with meningioma of the cranial base: secondary changes or tumor invasion. Neurosurgery 1999; 44(4): 742-6.
6. Phemister DB. The nature of cranial hyperostosis overlying endothelioma of meninges. Arch Surg 1923; 6: $554-72$.

7. Freedman $\mathrm{H}$, Forster F. Bone formation and destruction in hyperostoses associated with meningiomas. J Neuropathol Exp Neurol 1948; 7: $69-80$.

8. Balasubramanium V, Ramamurthi B. Meningioma. Neurol 1970; 18: 1: 81 - 8.

9. Guthrie BL, Ebersold MJ, Scheithauer BW. Neoplasms of the intracranial meninges. In: Youmans JR, ed. Neurological Surgery, ed 3. Philadelphia: WB Saunders, 1990: 3250-3315.

10. Kleihues P, Burger P C, Scheitauer B W: The new WHO classification of brain tumours. Brain Pathol 1993; 3: 255-68.

11. Jellinger K, Slowik F. Histological subtypes and prognostic problems in meningiomas. $\mathrm{J}$ Neurol 1975; 208(4):279-98. 